\title{
Didactic Potential of Using Mobile Technologies in the Development of Mathematical Thinking
}

\author{
Elena V. Soboleva ${ }^{1 *}$, Svetlana E. Chirkina ${ }^{2}$, Olga A. Kalugina ${ }^{3}$, Mikhail Yu. Shvetsov ${ }^{4}$, \\ Victor A. Kazinets ${ }^{5}$, Elena B. Pokaninova ${ }^{6}$ \\ ${ }^{1}$ Vyatka State University, Kirov, RUSSIA \\ ${ }^{2}$ Kazan (Volga region) Federal University, Kazan, RUSSIA \\ ${ }^{3}$ Financial University under the Government of the Russian Federation, Moscow, RUSSIA \\ ${ }^{4}$ Transbaikal State University, Chita, RUSSIA \\ ${ }^{5}$ Pacific State University, Khabarovsk, RUSSIA \\ ${ }^{6}$ I.M. Sechenov First Moscow State Medical University (Sechenov University), Moscow, RUSSIA
}

Received 1 November 2019 • Accepted 26 January 2020

\begin{abstract}
The relevance of the research is due to additional opportunities to improve the quality of teaching mathematics in a digital school, support professional orientation and self-determination of young people through the inclusion of mobile services and platforms in mathematical activities. The research problem is determined by the following contradictions: 1) between the capabilities of modern digital technologies in terms of improving the quality of mathematical training, the formation of universal skills required by the economy of the future, and the model implemented by educational institutions; 2 ) between the need to provide resources for solving problems of a socio-economic nature in the conditions of the fourth industrial revolution and the insufficient level of mathematical literacy of graduates. The purpose of this research is to study the didactic potential of mobile technologies to support mathematical education in a digital school while preparing specialists of the future. Moreover, the research offers a methodological approach to organize project activities of developing applications in terms of increasing the effectiveness of teaching mathematics and vocational guidance. The article clarifies the concepts "mathematical thinking", "mathematical literacy" for a digital school and describes the didactic principles of incorporating mobile resources into the educational space which increase the efficiency of training engineers of the future, support vocational guidance and self-determination. The author offers methodological methods and recommendations for organizing creative interdisciplinary project activities in order to develop mobile applications that contribute to the formation of qualities and skills forming the basis of mathematical thinking. The materials of the article can be used: firstly, to ensure the personalization of mathematical training in the course of creative, interdisciplinary, cognitive research activities of students while developing mobile applications, social integration and vocational guidance; secondly, to change the concept of mathematical education at school; thirdly, to improve the implemented model of education based on the traditional trajectory "preschool education-school-university-additional education" in the context of the new requirements of business, society, and the state for the training of highly qualified professionals in the professions of the future.
\end{abstract}

Keywords: mobile technologies, engineering and technical training, education, soft skills, digital economy, mathematical thinking, mathematical literacy, professions of the future

\section{INTRODUCTION}

\section{The Relevance of the Problem}

Ensuring technological development in the field of information technology, supporting the use of new digital services in various types of activities is an urgent area of modernization of modern science and education. The essence of the global digital transformation of the didactic system is to efficiently and flexibly apply the latest technologies to transition to a personalityoriented, continuous and non-linear educational 


\section{Contribution to the literature}

- Clarifies the concepts "mathematical thinking", "mathematical literacy" in the context of training specialists for the digital economy, in particular, engineering and technology.

- Studies the possibilities of using modern mobile technologies in order to increase the effectiveness of mathematical training in a digital school, support vocational guidance and self-determination of youth students.

- Formulates didactic principles of the inclusion of mobile technologies in a personalized environment for training engineering, technical and managerial specialists of the future for the formation of mathematical thinking as the basis for the introduction of innovations and the challenges of automation, globalization, and competitiveness.

- Offers materials for improving methods, tools, organizational forms of education, focused on the formation of mathematical thinking as the basis of cross-professional skills of future engineers;

- Describes basic ideas of a methodological approach to the use of mobile technologies in teaching mathematics to develop "smart" design solutions that meet the challenges of global digital transformation.

- Identifies possible problems of implementing the approach to the organization of research mathematical activity of students in the development of mobile applications focused on their intellectual development (systemic, critical and foresight thinking).

process. The digital era requires not only new skills from graduates of schools and universities, but also a different approach to organizing training for the professions of the future.

In these conditions, Russian and foreign researchers (Alexandrov, Ivanyushina \& Simanovsky, 2017; Hamada \& Hasan, 2017; Janelli, 2018; Kholodnaya \& Gelfman, 2016) prove the need to change the content, methods and organizational forms of education. The didactic process in the era of automation and globalization should be focused on solving the problems of the country's socio-economic development in the context of the fourth industrial revolution and the development of the digital economy.

According to Mora-Luis and Martin-Gutierrez (2020), the basis of the digital economy is the synthesis of previously existing material production (new materials, computer-aided design / production) and digital technologies that support the widespread use of artificial intelligence models and the development of the Internet of things. According to the idea, "smart products" will be the norm in a world where intelligent computerized devices (robots), the systems consisting of them, get opportunities for interaction in the preparation and deployment of automated production processes. The nature of the new industrial or technological (digital) revolution makes special demands on the highly qualified specialists of the future. Varshavskaya and Kotyrlo (2019), Kuzminov, Sorokin and Froumin (2019) reasonably conclude that graduates will require a high level of mathematical literacy thorough scientific and humanitarian training. When revealing the essence of the professions of the future, the authors focus on the abilities that are called "competences of the 21st century": fundamental theoretical knowledge, technology competencies (creativity, communication, self-organization, initiative, critical thinking, etc.).

Laso Salvador, Ruiz Pastrana and Marbán Prieto (2019) state that the main task in the digital educational space is to prepare an independent personality through the formation of different types of thinking, including mathematical.

Mathematical thinking in the new conditions of digital transformation is understood as creative, systemic, independent critical thinking. Only a person who thinks long-term, critically perceives the information, applies it in research, using fundamental mathematical laws and correct calculations and is capable of generating ideas in an uncertain future. There is a practical need to organize educational activities for the development of mathematical thinking. It integrates sustainable development goals into real projects, promotes them in science and industry, but also shapes thinking and general information culture of a member of the digital society.

Digital transformation of the manufacturing sector is already in process. However, when implementing technological innovations, problems arise due to insufficient training of engineering, technical and managerial personnel precisely in terms of the formation of qualities and skills that form the basis of mathematical thinking.

According to Záhorec, Hašková and Munk (2010), digital resources are not limited to students' motivation. The importance of using mobile applications to form a special set of knowledge, skills, and abilities that are defined as "digital literacy" is presented in (Hill \& Knutzen, 2017). This process is accompanied by simultaneous research (Chang et al., 2019; Ghazali, Mutum \& Woon, 2019; Mokretsov \& Zaslavsky, 2018), 
reflecting the capabilities of mobile devices and applications to improve learning.

The history of smartphones began in 1992, when IBM Simon was introduced to the world by IBM. Since that time, the smartphone has noticeably changed and become even "smarter". It is impossible to imagine a modern smartphone without mobile applications - from the standard applications "Calculator", "Contacts" and "Calendar" to specialized applications and games. Special applications - educational games - are gaining popularity. For example, the Skazbuka game (educational game for children from 2 to 7 years old) has more than 100 thousand downloads on the GooglePlay platform. The application Multiplication Table has more than 1 million downloads. Games for teaching foreign languages have more than 500 thousand downloads, applications for science and history - more than 100 thousand. Thus, mobile services with educational content as a special type of application are gaining popularity.

Indeed, it is difficult to imagine a modern student without a mobile device. Therefore, a didactic direction (the problem of using smartphones in the academic context) in the research of innovative teachers was logical. The mentor in the new digital school gets the opportunity to use the resources of mobile technology as a learning tool. For example, a teacher can use resources such as Quizizz, Kahoot, Triventy, etc. for students' control. These services allow to independently develop educational video games, quizzes, and interactive presentations. The student can independently choose the topics and directions necessary for him to plan the learning path. This process is accompanied by cognitive activity of manipulating visual images, objects, cards that need to be moved around the screen.

We have a number of methodologists and scientists' studies when mobile applications in education are used not only in finished form. The development of your own mobile application from a problem situation to commissioning supports training, cognition and upbringing in a digital school. Moreover, it prepares for successful professional activities, contributes to selfdetermination.

In the process of multi-stage creative activity, in particular when teaching mathematics, it is important to apply knowledge from various fields, skills of intersectoral communication and lean production; programming skills, teamwork; ability to mathematical activity (mathematical literacy, mathematical thinking). The largest role of the software component, technical support for the design and creation of the prototype is given in the preparation of engineering staff.

So, the development of mobile applications creates additional didactic opportunities for training professionals in demand in the digital economy, in particular, engineering and technology. The range of generated universal competencies is very wide, but the need to promote the development of personality's ability to formulate, apply and interpret mathematics in various fields of cognitive activity determines the relevance of the study in terms of the development of qualities and skills that form the basis of mathematical thinking.

\section{Aims and Tasks of the Study}

The purpose of this study is to uncover the didactic potential of mobile technologies for the development of mathematical thinking as an important competence of specialists of the future, and to offer a methodological approach to organizing project activities in order to develop applications in terms of increasing the effectiveness of teaching mathematics and supporting vocational guidance.

The main tasks of the research are:

- To clarify the concepts "mathematical thinking", "mathematical literacy" in the context of the training of engineers of the future in order to achieve the goals of the scientific and strategic development of the country;

- To describe the didactic principles of the inclusion of mobile resources in mathematical education in order to increase the efficiency of training engineers of the future, support vocational guidance and professional self-determination of youth;

- To formulate the basic ideas of the approach, which reflect the necessary changes in the methods, techniques, organizational forms of training for the targeted formation of mathematical thinking as the basis for the introduction of innovations and the implementation of automation, globalization and competitiveness trends;

- To offer methodological techniques and recommendations in order to organize creative interdisciplinary project activities for the development of mobile applications, contributing to the formation of qualities and skills that form the basis of mathematical thinking;

- To experimentally confirm the effectiveness of the proposed changes to improve the quality of teaching mathematics, formation of mathematical thinking and mathematical literacy, taking into account the challenges of the digital economy.

\section{LITERATURE REVIEW}

"Development Strategy for the Information Technology Industry in the Russian Federation for 20142020 and for the Prospect until 2025" is the basis for the development of the digital economy as a new concept in the national policy that take into account global trends in globalization and automation. When the main professional competencies demanded by society, state and business for the specialists of the future were stated 
in the Atlas of New Professions, it became obvious that the educational space faced new challenges requiring innovative pedagogical ideas.

Ponomarev and Dezhina (2016) underline the need to change the content, organizational forms, methods and teaching aids in the context of the development of a digital school. They offer a model for determining the scientific and technological priorities of Russia, consider possible tools and directions for their application. The authors examine in detail various digital technologies and a wide range of service functions that expand the interaction of participants in the digital educational environment.

Roshchina, Roshchin and Rudakov (2018), Lagunov and Podorozhnyak (2017), Alexandrov, Ivanyushina \& Simanovsky (2017), Shulgina et al. (2018) and others study the development of digital technologies, features of their inclusion in the educational and cognitive process, and program support. Other authors determine the potential of digital technologies (digital educational footprint) for the training of modern technical specialists, their support cognitive activities in solving practical problems (Galimova et al., 2019).

Modern industrial production cannot exist without the automation of computing processes, the use of cyberphysical devices and intelligent systems. Therefore, the formation of relevant skills in the training of engineering, technical and managerial specialists of the future is of particular importance. This position is confirmed by Osipova, Gafurova and Rudnitsky (2019). They study the formation of Soft skills for bachelors in the educational program of the Metallurgy direction. Filatova, Scheinbaum \& Shchedrovitsky (2018), using the example of Gubkin University, shows the effectiveness of using interdisciplinary trainings in the virtual environment of professional engineering activities to form such a universal skill as "teamwork ability". Problems of training engineers in modern schools, their lack of demand for the digital economy are presented by Varshavskaya and Kotyrlo (2019). Kuzminov, Sorokin and Froumin (2019) point out benchmarks for training engineering specialists for the "new" industry, in particular, a benchmark for increasing mathematical literacy, taking into account human capital as necessary conditions for sustainable development.

Studying various aspects of the digital economy, Perelet (2019) reasonably argues that achieving strategic priorities is impossible without maintaining a balance between the fundamental nature of the knowledge and the formation of the skill to learn. The digital economy of the country determines the need for training specialists using digital technologies in production, automation of calculations, and as a tool for their mathematical cognitive activity.
Analyzing the concept "mathematical thinking", the author distinguishes two diametrically opposite approaches in the scientific community. Most authors explore the nature of mathematical thinking as a special high skill thinking (Kholodnaya \& Gelfman, 2016). Others view this term as synonymous with "critical" or "systemic thinking" (Tregub, 1973). Kaplunovich and Petukhova (1998) propose to consider the transformation of any information containing mathematical material as the result of the interaction of four components of mathematical thinking: motivational, cognitive, informative, operational.

The problem of the mathematical thinking development is of particular interest among scientists during the formation of the information society (Tsymbalist \& Grigoryev, 2003) and nowadays, when the Internet and digital technologies are applied in all areas of activity (Karabelskaya, 2017). The reason for the spread of mathematical activity supported by software, precisely in the socio-economic sphere, is due to the formation in society of an information space saturated with mathematical models and algorithms and the activation of the computational aspect of social practice. As a result, the goal is to develop mathematical thinking as the basis of an individual's information culture (Tsymbalist \& Grigoryev, 2003).

Subsequently, Pantseva, Toisheva and Borisova (2019) develop these ideas and characterize the essence of mathematical activity, the components of mathematical literacy. Schiptsova, Shchiptsova and Mustafina (2012) highlight the constructive abilities in the structure of mathematical literacy of future professionals: the ability to integrate knowledge from different fields of science when solving problems. They emphasize that the fundamentalization of mathematical training plays a leading role in the development of logical and professional innovative thinking of students through the understanding of multifunctional structures and schemes (as means and methods of cognition) similar to mathematical structures and schemes.

Urvanova (2018) justifies the need for focused pedagogical support for the transfer of mathematical knowledge and skills using new digital technologies. The key point of her work is in the problematic approach in organizing the corresponding cognitive activity of students in order to promote the development of creative non-standard thinking.

Karabelskaya (2017) proves the fact that for the development of mathematical thinking as a universal competence, it is necessary to include differentiated creative tasks in students' cognitive activity, which activate personal and professional growth, enhance independence in reasoning, self-development, freedom to choose tools for resolving a problem situation, design the optimal path of knowledge, analyze and correct the educational route. According to Karabelskaya (2017), 
teaching mathematics in a digital school shouldn't be a formal application of information resources and technologies. Mathematical modeling, the inclusion of mathematical tools in applied research of an interdisciplinary nature should help in solving these problems. Other authors prove that cognitive activity in a dynamic environment has a positive effect in terms of developing intellectual thinking and improving the quality of education in general (Soboleva et al., 2018).

Urvanova (2018) presents in detail a generalization of Russian studies on the problem of determining the essence of the social type of thinking and the mathematical type as its separate manifestation, shows difference between the concepts "mathematical consciousness", "mathematical literacy", "mathematical culture" and underlines the need to improve mathematical education in modern society. We agree with the position of the author, who considers "mathematical competence" to be the individual's ability to intellectual activity, subordinate to mathematical laws, aimed to study the world and determine patterns between various objects and phenomena of reality.

The last thesis is developed by Smirnov, Zykova and Tikhomirov (2019). They discuss the processes of managing school mathematical education using computer and mathematical modeling. The study identifies the features of complex mathematical concepts, theories, concepts through visual modeling. Subsequently, Perminov, Gadjiev and Abdurazakov (2019) support the position that the era of the postindustrial knowledge society differs from the previous socio-economic period by full automation, digitalization, interdisciplinary integration of various scientific fields, where mathematics has special meaning. According to the authors, the language, tools and methods of digital technologies have become universal research tools in the fields of physics, biology, chemistry and engineering, production organization and in many other theoretical and applied fields of activity. Therefore, the demand for highly qualified personnel with fundamental knowledge of mathematics and able to apply them in intellectual activity is increasing (Nagornaya, 2015). Such specialists should not only transmit information. The obtained mathematical information, facts should be the starting point in their professional, computational, social, communicative practice. The authors negatively relate to the growing imbalance between the necessary fundamental mathematical training for graduates and the implemented model of mathematical education at school (Perminov, Gadjiev \& Abdurazakov, 2019).

Innovative educators suggest using chess game activity to enhance mathematical thinking (Dvoryatkina et al., 2019). The exclusivity of skills to play chess is explained by the position that the uncertainty of the move on the board is similar to the uncertainty of the conditions of the future. It is impossible to build a game strategy without a creative approach to applying theoretical knowledge, ability to think outside the box, long-term and "ahead of the curve". The educational effect of integrating mathematical knowledge and chess skills is considered from the point of view of the components of theoretical thinking and is determined by the student's creative choice in the search for alternative solutions. The authors distinguish the intellectualheuristic, intellectual-logical, motivational and reflective stage of educational and cognitive activity. Scientists state that creativity is always accompanied by emotions. Overcoming difficulties in the search, the joy of discovery, communication in a team and joint experience enhance memorization of theoretical material, understanding of logical connections.

Thus, we conclude that some researchers have negative attitude to the use of digital technologies in mathematical activity, stating that computational activity is reduced to automating work with a calculator, spreadsheet editor, etc. (Nagornaya, 2015; Perminov, Gadjiev \& Abdurazakov, 2019). Failure to perform simple mental mathematical operations leads to a fall in the general information culture. Most authors focus on the need for a systematic development of scientific mathematical thinking in the structure of the competency-based approach to education (Kholodnaya \& Gelfman, 2016; Panceva et al., 2019; Tsymbalist \& Grigoryev, 2003). Scientists distinguish didactic, motivational and behavioral criteria for the formation of mathematical thinking. The authors propose an educational model that implies the integration of educational, gaming, professional and social activities of students (Urvanova, 2018). In their practice of forming mathematical thinking, they apply a system-activity approach that involves a research focus and creative interdisciplinary nature of students' project activities (Dvoryatkina et al., 2019). They denote the importance of taking into account age-specific features and individual styles of knowledge in planning mathematical training.

At the same time, we cannot deny the positive resources of digital technologies for supporting mathematical activity, for example, the capabilities of the "big data" analysis, including the diagnosis and adoption of "smart" verified decisions (Karabelskaya, 2017). It is of great importance for the engineer of the future to have fundamental knowledge of innovations in science, industry, education, etc., in order to possess the resources to maintain a balance between the needs of the high-tech industry and the needs of society, the formation of a special mathematical thinking of a person in the educational environment using digital technology tools (Soboleva et al., 2018).

A number of scientific research (Mokretsov \& Zaslavskiy, 2018) reflect the capabilities of mobile devices and applications to increase the effectiveness of training. Zasedatel and Serbin (2014) study the specifics of pedagogical support for using mobile devices in 
training, identify their significance and didactic functions. They describe the main advantages and disadvantages of mobile technologies in detail, opportunities to include students in the practice (Usol'tsev \& Antipova, 2019). Moreover, the authors analyze existing mobile solutions, their interface, and technological support features (Mokretsov \& Zaslavskiy, 2018). The authors formulate requirements for the content of mobile educational content: compactness, ergonomics, access on demand, a range of opportunities, ensuring equal access to education, personalization of training, feedback and assessment of learning outcomes, support for situational learning, the development of lifelong learning, providing a link between formal and non-formal learning, inclusive education. Also they point out problems of using mobile educational content: technical problems (adaptation of applications, information security problems, lack of uniform standards for content development depending on the system, etc.); social and educational problems (difficulties with choosing a mobile device, problems with the security of various data, etc.).

At the moment, mobile applications are actively used on two main platforms (operating systems): Android from Google, iOS from Apple. However, at the moment, most of the existing mobile tools and applications are included in the cognitive process only at some particular stage of activity to solve a specific system of tasks for educational and career guidance purposes (Shulgina et al., 2018), or with the aim to develop mental processes: thinking, memory, attention, and imagination (Kholodnaya \& Gelfman, 2016). In most cases, the mobile application is selected as a finished product for use in didactics. Implementation features, program code, functionality, understanding of practical significance are hidden to users.

According to Mokretsov and Zaslavsky (2018), it does not meet the specifics of training specialists in engineering and technical fields, the priority areas of variability, personality-oriented nature of education and training. These reasons significantly reduce the didactic potential of mobile applications in terms of increasing the effectiveness of training and supporting career guidance.

Moreover, there is only a few numbers of works that prioritize support with technologies specifically for intersectoral communication in the study of mathematics, in particular creative thinking (Karabelskaya, 2017).

Thus, this study will examine in detail the methodological features of the inclusion of mobile technologies in a personalized environment for the training of engineering and management specialists of the future for the formation of mathematical thinking as the basis for the introduction of innovations and the challenges of automation, globalization, and competitiveness. The considered examples of projects can be implemented in various software environments, their content is determined by the developers, each topic is based on a specific problem situation of a mathematical nature. The technical design and protection of the results of cognitive mathematical activity is necessary.

Gault (2019), Scholtz, Burger and Zita (2016), Zafoschnig (2018) study features of training of engineering specialists. They note that in the development of modern education there was no period comparable to the current changes in pace and quality, which is especially noticeable against the rapid growth of engineering sectors in the global economy. These trends place higher demands on engineering education in terms of effective pedagogical interaction. The key idea of Zafoschnig (2018) is that cooperation, multimedia communication and the joint solution of complex interdisciplinary problems (including mathematical ones) should become the basis for training specialists for the "new industry".

Thus, increasing mathematical literacy and the formation of a critical worldview is the basis for preparing future generations. Mathematical thinking is revealed through the ability of a person to argue his actions and ideas. Raman (2003) explores the nature of the proof, various approaches to argumentation in the course of mathematical activity. The author shows the difference between mathematical proof and other sciences. The assessment of literacy, mathematical language plays an important role in assessing the formation of mathematical thinking. The scientist notes that in modern mathematical education, great attention is paid to language as a tool for expressing thoughts with unique cognitive capabilities. These ideas are reflected in modern scientific works (Gut \& Mirski, 2018). The authors state that, through language, a person unites information received from spatial perception and mathematical activity. Spatial cognition gives information about the location of an object and its properties, such as color or size. Mathematical knowledge operates with numbers. Only language allows to integrate these contents into a single whole the known.

Li, Mok and Cao (2019) reasonably argue that mathematical thinking is one of the most important goals of mathematical education, as it can support sustainable mathematics education. Their study summarizes the experience of teaching mathematics in Chinese schools.

The development of mathematical thinking presupposes a problematic approach to education, which determines the importance of the teacher's work in overcoming fear among students for mathematical research activities (Fouze \& Amit, 2018; Lee' 2018; Ramdani, Syamsuddin, \& Sirajuddin, 2019; Tambunan, 
2019). The authors also believe that it is necessary to take into account students' previous experience in the study of new methods of solution.

Sayed (2017) highlight important points for the current study. Here we present an approach that necessitates the integration of digital learning and the development of critical thinking of students through the study of mathematical concepts. The aim of Harjo, Kartowagiran and Mahmudi (2019) is to develop tools for building critical thinking skills that meet the requirements of reality. According to scientists, a multistage research activity from design to implementation is the most productive.

Other authors cite experimental data that the inclusion of digital technologies in mathematical education qualitatively increases the effectiveness of instruction and contributes to the development of critical thinking skills. Sayed (2017) identifies various criteria for assessing the formation of critical thinking, in particular, when working with tables and Internet resources. Students show the ability to reason, argue, and search for a solution to a problem, when solving an interdisciplinary problem (ethics, law, computer science).

Of course, programming environments provide the most significant effect for the development of mathematical thinking (Buteau, Sacristán \& Muller, 2019; Zeynivandnezhad \& Bates, 2018). The authors formulate an instrumental approach to the use of computer programming technology for applied mathematical research. The approach describes a holistic process from motivation to the presentation of the results of mathematical programming activities.

More (2018) summarizes the experience of organizing mathematical competitions, examines the role of student involvement in competitive mathematical activities in order to increase motivation and curiosity, gain experience, support innovation and research. Competitive practice makes it possible to understand the application of mathematical laws and concepts in practice. Students presented the results of their cognitive mathematical activities in various forms, such as a model, poster, animation, performance, through art and poetry. The focus of the competitions was on the use of computing tools and modern technology in order to emphasize the connection of mathematical concepts with engineering applications in real life. del Río, Sanz and Búcari (2019) assess the didactic potential of using media resources in education. The work is valuable as the authors analyze the experience of studying mathematics at the School of Engineering. The authors experimentally verify that educational electronic resources contribute to the development of critical thinking.

Radović, Marić and Passey (2019) offer a methodological approach to the use of ICTs to enhance the interaction of participants in the educational process (Radović et al., 2019). The authors consider the integration of ICT in the practice of teaching and learning mathematics, evaluate new ways of developing mathematical thinking.

Fahuzan and Santosa (2018) suggest increasing students' motivation to learn mathematics through gamification. The authors state that schoolchildren often consider mathematics to be a complex subject, therefore they need additional motivation to study it. A roleplaying game on a mobile platform is proposed as a means of gamification.

Malkawi, Alhadrami and Aljabri (2019) describe in detail the possibilities of developing an interactive mobile application to improve skills in solving problems in the field of physics. The solution to a problem is an essential part of the educational process. Relevant cognitive activities include understanding, recall, critical thinking, and the application of mathematical skills. According to the authors, the didactic value is not the result of solving the problem itself, but the process of its perception, search and discussion. The obtained skills form the basis of mathematical thinking. In order to support students in solving problems, the teacher of a modern school should use mobile technology. Malkawi, Alhadrami and Aljabri (2019) offer an application development (Android) that focuses on guiding, helping, encouraging, motivating students and creating a more interactive and engaging environment. It is built on an algorithm that relies on the main steps in solving problems.

The results presented above prove an improvement of the quality of mathematical knowledge after active metacognitive involvement in the development of mobile applications. Thus, creative research work and the implementation of projects contribute to the formation of mathematical thinking.

The need for personalization of training in a digital environment is justified by De Corte (2019), who study the design features of the educational process and the creation of highly effective educational environments for the development of self-regulation skills.

Many foreign scientists study the possibilities of using not only traditional digital resources (online courses, electronic textbooks, websites, simulators), but also mobile applications of the interactive game format in order to improve the quality of training. Petko et al. (2019) experimentally prove that mobile technologies open up new ways to stimulate reflection in education. According to Záhorec, Hašková and Munk (2010) the potential of digital media is not only limited to student motivation, but also contains resources: for working with multimedia content, for timely and "targeted" hints in intellectual activity, for the exchange of experience of all participants in the digital educational space. Saritas (2013) describes the specific computing functions of a 
smart device. The author notes that smart devices form a new ecosystem, a new paradigm for the smart environment.

Hill and Knutzen (2017) underline the importance of using mobile applications to form a special set of knowledge, skills, and abilities that have been conditionally defined as "digital literacy". Foreign authors also introduce a term "computational thinking," the formation of which is most effective in solving a series of problematic problems (Nissen, Lezina \& Saltan, 2018). Wilmer and Chein (2016) study user-mobile device interaction patterns, dependencies, and preferences. Taneja et al. (2012), Hunt et al. (2018) analyze in detail the cognitive, psychological components of using modern digital resources. Fritsch and Wyrwich (2019) show the potential of digital technology for professional self-determination. They point out that the availability of specialized knowledge is extremely important for the activities of new IT companies, and the strengthening of an interdisciplinary knowledge system should be a key element of all technical initiatives aimed to stimulate entrepreneurship in this sector.

Hamada and Hassan (2017) prove the important statement that digital interactive teaching tools provide effective tools for computer science and engineering. The authors focus on the motivational aspect and the quality of training.

The most recent analytical work on the research problem confirms the position that training engineers who can solve global problems is today a key aspect of higher education (Mora-Luis \& Martin-Gutierrez, 2020). Research interdisciplinary activity has the greatest potential (Catarino et al., 2019; Zafoschnig, 2018). And finally Hamid et al. (2017) take into account the use of digital resources, such as social Facebook network which has great didactic potential for the formation of mathematical thinking.

Thus, summarizing the results of the foreign literature review, we come to the following conclusions: mobile technologies have powerful didactic potential for improving the quality of teaching mathematics and supporting the professional development of personality. The formation of mathematical literacy is the basis for the development of new digital solutions. Digital technologies can and should be used to train engineers of the future, who have universal (interdisciplinary) competencies (including the skills of mathematical research).

This study will present a methodological approach that takes into account the achievements described above, and the priorities and traditions of the Russian education in the context of the digital economy.

\section{MATERIALS AND METHODS}

\section{Theoretical and Empirical Methods}

To determine the trends and priorities of the modern digital educational environment, challenges to training specialists of the future, in particular, engineering and technology, we have analyzed psychological, pedagogical, methodological and technical literature of foreign and Russian authors. We have analyzed specific developments of subject teachers, scientific and methodological literature on using digital tools in education in order to study possibilities of digital interactive technologies to increase the effectiveness of teaching mathematics, supporting professional orientation and self-determination.

Moreover, we have used the method of analysis of the concepts of mathematical and engineering education, scientific and technological development strategies of countries, Atlas of New Professions in order to determine the importance of mathematical competence in the soft skills system, to formulate problems of the formation of mathematical thinking and mathematical literacy as important universal professional competencies in the digital educational space for training engineers of the future.

Then, using the forecasting method, we have determined the didactic potential of mobile technologies for organizing the cognitive activity of students in carrying out research projects with mathematical content and have formulated a hypothesis regarding qualitative changes in the results of teaching mathematics.

The method of systematization and generalization of facts made it possible to formulate didactic principles, the main provisions of the methodological approach.

The main statements of the system-activity approach were the methodological basis for the study of the effectiveness of developing mobile applications for the formation of the demanded competencies of engineers of the future (using the example of mathematical thinking and mathematical literacy). The system-activity approach has allowed to justify the fact that the creative interdisciplinary project activity of students contributes to the active assimilation of knowledge and the formation of methods of student's activity through motivated and purposeful solution of educational mathematical problems.

Using the Design Based Research (DBR) method, we have studied the results of cognitive mathematical activity of the joint work of teachers and students. The method of Venn diagrams, as a method of critical reflection, made it possible to identify the general results of projects, formulate problems, offer concrete recommendations for educators, and generalize knowledge. 
At the stage of the pedagogical experiment, we used the following empirical methods: observation, questionnaires, testing, analysis of the results of educational and cognitive activities of students. These methods made it possible to obtain information about real changes in motivation, involvement in a problem situation of a mathematical nature, the activation of students in cognition, the formation of research skills and independent work as important skills in mathematical activity to prepare for a successful professional trajectory.

\section{Research Base}

Testing, synthesis and implementation of research results are carried out:

- by teaching courses "Information Technologies in Pedagogical Activities", "IT in the Processing of Academic Achievements and Scientific Research", "Technologies for Creating Curriculums" for students of the direction 44.04.01 Pedagogical Education (Master's programme) based on materials developed by the author (Soboleva, Karavaev \& Perevozchikova, 2017). The course has been taught at the Vyatka State University of Humanities and Kazan (Volga region) Federal University since 2018, and at the Vyatka State University since 2016.

- by teaching the course "Theory and Methods of Teaching Computer Science" for students of the direction 44.03.05 Pedagogical Education (two education profiles) based on materials developed by the author (Soboleva, Karavaev \& Perevozchikova, 2017). The course has been taught at the Vyatka State University of Humanities and Kazan (Volga region) Federal University since 2010, and at the Vyatka State University since 2016.

- while organizing the training in computer science at the Kirov Lyceum of Physics and Mathematics.

The effectiveness of students' cognitive activity in developing mobile applications with mathematical content, including the implementation of creative interdisciplinary research projects, taking into account the challenges of the digital economy and the requirements of high-tech industrial production for engineers of the future, was assessed during the pedagogical experiment. 50 students took part in the pedagogical experiment. The experimental ( 26 people) and control (24 people) groups were formed. The experiment was conducted in specially equipped computer science classes with the same software.

To process the results of the pedagogical experiment, we used an analysis of arbitrary contingency tables using the Pearson $\chi^{2}$ criterion.

\section{Stages of the Research}

The study had three stages.
The first stage was a stating experiment: we studied the state of actual didactic problems of the development of mathematical thinking as an important skill for obtaining a demanded profession in a modern digital society. We also assessed the potential of interdisciplinary project activities to develop mobile applications in terms of the formation of mathematical literacy. Therefore, we analyzed the scientific literature on the research problem, studied and compared analysis of teaching experience in Russia and other countries in order to identify the necessary changes.

The second stage was the development of didactic principles, the description of the didactic potential of mobile technologies for the training of engineering, technical and managerial personnel of the future in terms of the formation of popular universal competencies, in particular mathematical thinking, as the basis for introducing innovations and responding to the challenges of automation, globalization and competitiveness.

The third stage of the study was the experimental teaching and improvement of the basic ideas of the approach in relation to the identified requirements of the digital economy and the formation of universal competencies. Teaching was accompanied by constant monitoring of the results of students' research projects, which allowed to consistently improve the proposed methodological ideas. Discussion of the research results took place in the form of publications in journals and reports at conferences at various levels.

\section{RESULTS}

\section{The Main Provisions of the Methodology}

In the presented study, we consider the concept "mobile application" to be a component installed on a mobile device under a specific platform that controls the user interface and logic of the device.

"Mathematical thinking" for digital educational space is the integrative quality of a person, which is characterized by the mobility of knowledge, aimed to find the optimal solution to engineering problems and satisfying technical needs.

We include educational and cognitive situations in mathematical cognitive activity when it is required to formulate a situation mathematically, apply mathematical concepts, facts, and reflection procedures; interpret, use and evaluate mathematical results.

The mathematical thinking of a member of a society subject to the trends of digitalization, automation and globalization should be considered as an integral component of the information culture of his personality. The key idea of the development of mathematical thinking in a digital society is the necessarily problematic nature of education aimed to form mathematical literacy. Moreover, the corresponding 
cognitive activity should include solving educational and practice-oriented tasks that involve several options for resolving, developing various future scenarios depending on the joker event. Such multivariance should take into account the various priorities and norms of society.

The most important characteristics are: the quality of mental operations aimed to solve situations and problems of a mathematical nature; consistency in the acquired mathematical knowledge; consciousness in understanding the integrity, systemicity and processuality of the surrounding world; ability to predict the end result; the ability to put forward hypotheses and choose the most acceptable from the set of possible options; ability to establish causal relationships.

We propose to consider the structure of mathematical thinking through the integration of the cognitive, prognostic, practice-transforming and motivationalvalue component.

The demanded qualities of the personality are mathematical education, mathematical ingenuity, development of critical thinking, formation of awareness of relationships between technology, society and the individual.

According to the literature review, we can reasonably conclude that the range of digital school software in relation to the development of mobile applications is very diverse: Apprery.io, Mobile Roadie, Android Studio, Good Barber, Eclipse, etc. Let us underline the objective opportunities that mobile technologies provide for the development of "smart" decisions in terms of the development of mathematical thinking, contributing to the formation of universal cross-professional competencies:

- development of skills of non-standard, creative activities (due to the interface and variety of functionality, through the multivariance of the solutions);

- development of information search skills, allocation of source data and result;

- development of skills to highlight essential properties, comparison, classification on various grounds;

- development of writing information model skills in the language of mathematics;

- acquisition of skills for predicting the future and making decisions in the conditions of "uncertainty";

- teamwork skills (forums, chats, collective discussion);

- ability to process messages from the system, interpret them and make a responsible decision (when interacting with a software tool, an operating system);
- skills in mathematical activity (filling in application content);

- gaining experience in communication and recording mathematical expressions in various languages (interface language, interaction in a chat or forum).

The study of fundamental theoretical foundations, laws of logic, etc. is of great importance in the direction of the formation of mathematical competence. Therefore, the development of mobile applications should be accompanied by the study of specialized information sources with mathematical content, laws and concepts, recent mathematical discoveries, etc.

Particular attention should be paid to the development of mobile applications and the information culture in general. Mathematical activities when working with mobile technologies should include the following components: mental operations aimed to resolve practice-oriented situations and problems; mathematical knowledge and understanding of the integrity, consistency of the information model; ability to predict the end result; the ability to put forward hypotheses and choose the most acceptable from the set of possible options; ability to establish causal relationships.

The practical application of these types of cognitive activity, aimed to form mathematical thinking and mathematical literacy as the basis for the demanded cross-professional competencies in accordance with the features of the "Atlas of new professions", allows to change the pedagogical principles applied to the programs in the direction of training engineers of the future:

- systematicity: implemented through the structure of a mobile application, through the logic of building each specific lesson. The selection of topics should provide an integrated system of knowledge both in the field of programming and knowledge from the fundamental foundations of mathematics, mechanics, physics and computer science;

- humanistic orientation of the pedagogical process: topics of interdisciplinary projects for modeling "smart" solutions should be developed taking into account the requirements of maintaining a balance between the formation of fundamental theoretical knowledge and the acquisition of the necessary skill "to be able to learn"; priority areas of development in the field of technology and the needs of education, society; the need for self-determination and socialization of the individual;

- connection of the pedagogical process with life and practice: training at each level of study should be implemented in such a way that the process of developing a mobile application is preceded by a mandatory (necessary for life in a modern digital society) thinking process. During an interdisciplinary 
practice-oriented activity, the student masters such intellectual skills as structuring, planning, optimal interaction with the environment, forecasting results (foresight thinking), information retrieval, classification, building conclusions, etc.;

- students' awareness and activity during studying: creative problematic activity activation of the perception of theoretical fundamental knowledge in mathematics, their comprehension, self-processing and application;

- fixing knowledge: achieved by repeated (specially methodically organized through a system of techniques and methods) targeted repetition and training to minimize the risk of all users;

- visibility: allows to take into account all individual psychological styles of cognition;

- education and support for socialization: in addition to increasing the motivational-value component, the development of mathematical skills, mental and moral qualities in the development of applications, information interaction, the person assimilates and demonstrates his own norms and rules of behavior in society;

- principle of an individual approach to education: it is implemented both through building a system of tasks and at the level of individual personal communication between the teacher and the student, at the level of three-way interaction "teacher - student - mobile (automated) device".

For the successful implementation of the proposed principles in the formation of mathematical thinking in the process of developing mobile applications for the training of engineers of the future, it is necessary to have a set of organizational and pedagogical conditions, providing:

- the educational process based on the integration of fundamental scientific facts / concepts and applied software / digital technologies;

- implementation of interdisciplinary research tasks of a problematic nature with mathematical content;

- actualization of students' needs to obtain the demanded profession of the future for successful socialization through the practice of team activity (the whole group works on the project entirely), interaction (situations where the development of each application function is given to an individual student).

Thus, we have obtained the following theoretical results: described learning objectives, i.e. requirements that the state, society and business make for the professionals of the future; defined the principles of learning necessary to consider when developing mobile applications in terms of the formation of mathematical thinking.

\section{Working out a Mobile Application to Support the Development of Mathematical Thinking}

In our opinion, for the effective use of mobile technologies in mathematical education with an orientation towards the training of engineers demanded by the digital economy, it is necessary to consider:

- didactic component: goals and objectives, mathematical content, problem situation, etc.;

- software and hardware support: selection of a digital platform (Android, IOS), hardware (phone, tablet, laptop), software - a programming system or a ready-made software solution (Blippar, Geocaching, iSpbGuide, Machinarium, etc.), interface languages;

- psychological component (age, individual physiological characteristics of participants, attitude to the environment, values and motives);

- methodological support - organizational stage, project scenario, methodological recommendations for developers and educators;

- application: design, functionality, customer focus, language support, work with multiple devices, etc.

Let us present each component in detail using the example of developing mobile applications that support mathematical learning with the tools of the visual programming environment MIT AppInventor. This environment was originally worked out as quite simple, intuitive and intuitive for designing and developing fullfeatured applications for smartphones and tablets.

AppInventor is quite simple, block-based, easy to create digital applications. Mastering basic functions and commands does not require special high-level programming skills. The AppInventor project was originally aimed to popularize application development by providing the ability to move from ready-made products to developing your own resources. The development of the ability to analyze the system, desire to create new applications, ability to try oneself in something unusual and unknown is far from the whole potential of this environment. The use AppInventor in the educational process allows to solve a wide range of practical problems. It is possible to use the original (English) version if the level of language is Elementary (elementary level), but Intermediate (middle level) is best. The latter facilitates the use of foreign literature on AppInventor in terms of studying the environment and application development.

Examples of possible interdisciplinary projects:

1. The project "Automation of cargo transportation". One jet aircraft consumes 15 tons of fuel and 625 tons of air per 1 hour and emits 46.8 tons of carbon dioxide, 18 tons of water vapor, $635 \mathrm{~kg}$ of carbon monoxide, $635 \mathrm{~kg}$ of nitrogen oxides, $15 \mathrm{~kg}$ of sulfur oxides and $2.2 \mathrm{~kg}$ of solid particles into the environment.

The average time of keeping these substances in the atmosphere is approximately 2 years. The AN-124 
aircraft can transfer 120 tons of cargo if the flight range is $4800 \mathrm{~km}$, the average speed is $750 \mathrm{~km} / \mathrm{h}$. The average car emits 135 kilograms of carbon monoxide; 25 kilograms of nitrogen oxides; 20 kilograms of hydrocarbons; 7-10 kilograms of benzpyrene; 4 kilograms of sulfur dioxide; 1.2 kilograms of particulate matter per year.

The company does cargo transportation, Moscow Irkutsk $(4800 \mathrm{~km})$. It can use an airplane (a plane needs to make 2 flights a month) and a truck (4 trucks in 1 month).

The task is to develop a prototype application that allows to optimize the choice of type of transport in order to rationally use it under these conditions.

2. Development of a converter to transfer length (meters in fathoms, arshins, versts), mass, etc.

3. Development of a prototype system that analyzes human emotions in order to recognize students' mood.

\section{The project "City Monuments".}

The project idea: there is a list of city monuments with pictures and GPS coordinates. The user selects interesting monuments from the list, puts "ticks" (marks) and offers the system to build the corresponding virtual route.

Then there is a transition to another screen with a map where selected monuments (photos, text, music) are fixed. After studying the selected monuments and their history, the application offers the user a series of questions about visited attractions. Based on the results of the virtual tour, the application issues a particular certificate (for example, a beginner, a connoisseur of the city of the 1st level).

5. Implementing of an automatic device for diagnosing room temperature and signaling the need to change the room temperature to a comfortable one. You can manually configure the device and identify possible super-systems of the developed device and modification options.

6. Development of a prototype application that allows to optimize the choice of dishes in the canteen.

Consider the engineering development of the device to solve the following engineering and practical problems (actual problem situation): to develop a mobile application-project "Smart Canteen".

Let us describe the problem situation. Suppose each student has the opportunity to have breakfast and lunch in the school cafeteria. To do this, the schools increase the time for a break and make up a daily menu. But there can be the following problems: not everyone is satisfied with the set of dishes that they offer; many students want to choose their own menu; it is necessary to take into account the students' attitudes towards a healthy lifestyle. It is required to prepare a list of dishes recommended for a healthy diet.
Today, there is no possibility of mass introduction of school canteens into the option of choosing dishes according to students' preference due to the service time and other resource costs.

It is required to propose a "smart solution" that can optimize the work of the canteen using digital technologies in the field of software process control and mobile development.

As a motivation of such a project, we can conduct students' survey: "Would you like your canteen to be equipped with such a smart device?"

The goal of the project is to ensure a healthy diet by individual approach to meal selection without attracting additional resources. The product idea (design solution) is: a mobile device for automating the selection and delivery of dishes in the dining room.

In this regard, the sequence of stages of students' cognitive activity during the implementation of the project is the following:

- introduction to the problem through a conversation with a group of students (giving specific life examples with the problem situation; bringing undeniable facts that the solution to the problem situation cannot be postponed);

- study of the problem (group discussion; analysis of materials in the public domain, search for existing technical solutions; study of the advantages and disadvantages of the solutions);

- distribution of roles in the project team, taking into account the individual interests and values of the participants;

- search for technical solutions (brainstorming; focal object method; methods for the theory of solving inventive problems and methods for finding technical solutions; inventive workout method, concept of productive thinking; method of engineering constraints);

- preparation of technical specifications for the development of a software solution indicating the duration of each stage;

- carrying out the stages of the project, designing and programming the device;

- filling the content of the application;

- a test run and a series of tests to confirm the operability of the device (search and eliminate shortcomings);

- final revision of the device, development of a prototype device;

- presentation of the results of the project in the form of a presentation with a demonstration of the prototype;

- preparation of technical documentation in the form of an engineering book; 
- summary, group reflection.

This project was implemented after gaining basic skills in working with Arduino microcontrollers, mobile development and the basics of project activities. The project involves two to three months for the production of a working prototype.

The product algorithm:

1. The choice of dishes using a mobile application. Data on the selection is transmitted to the device in the form of a user card.

2. Reading data from the card. User Name Check / Read. As soon as the user goes to the device and puts the card in, he has a lunch from the selected dishes

3. Preration of lunch. The application collects the selected dishes and "packages" it.

\section{Lunch delivery.}

The interdisciplinary creative result of the project activity is an application program for selecting dishes and ordering lunch, a device for automating the collection and delivery of lunch in the school cafeteria.

As for the results of the project activity in terms of the development of mathematical thinking, we can note the economic component when counting the products emitted in the canteens and material costs of parents. It also takes into account the social component of mathematical learning: minimizing the risk of systematic student refusal to eat in canteens due to a violation of his values.

Let us list some of the Soft Skills that are formed during the design process: the ability to defend one's point of view; the ability to search for information in free sources and structure it; the ability to organize independent research activities in order to design a new technical device or improve the characteristics of the old one; the ability to assess the necessary amount of professional knowledge and skills necessary to solve a particular problem; the ability to assess the aesthetics of a particular decision and its compliance with the norms of public morality; critical thinking and the ability to objectively evaluate the results of the work.

The basic Hard Skills, which are formed during application development, are: the ability to find a solution to a problem under resource constraints, to find an alternative solution; ability to compose a program algorithm; knowledge of programming microcontroller platforms in the Arduino IDE; the ability to receive and process information with Arduino - compatible modules; the ability to create Android applications in the visual development environment of MIT App Inventor; the ability to organize full multiple operational tests aimed to study and improve the individual characteristics of the created technical device.

If necessary, you should explain safety measures. The students write all mathematical calculations, model tests, identified technical features for operation in the engineering book.

Thus, we have described the basic ideas of the methodological approach for including project-based interdisciplinary activities of students to develop their own mobile applications for the formation of crossprofessional competencies (using mathematical thinking as an example) in terms of training future specialists capable of making a breakthrough in modern science and technology.

\section{Experimental Evaluation}

\section{The ascertaining stage of the experiment}

At the first stage of the experiment, students were given a control task to work with information, with a model in accordance with the indicated demanded skills and abilities that form the basis of mathematical thinking. Thus, it was possible to collect experimental data on 50 students (30 respondents in 2017-2018, 20 students in 2018-2019). According to the result of the preliminary control test, students (participants of the pedagogical experiment of three years) had almost the same initial level of preparedness. So, we can consider them as a general sample of 50 people. Thus, the experimental (26 students) and control (24 students) groups were formed. The experimental group had $65 \%$ of girls and $35 \%$ of boys.

\section{The forming stage of the experiment}

The control group had classes according to the traditional teaching methodology of studying the basics of algorithmization and programming, without special organization of cognitive mathematical activity. They were active and independent in research, which was organized in the form of practical work with mobile technologies, performing tasks on specific topics. Students from the experimental group were trained according to the described option.

To diagnose the input conditions in the model of the pedagogical experiment, we conducted a survey including a series of tasks. The examples of tasks are:

1. A zinc-mercury battery weighs about 12 grams. When disposing of batteries, graphite is released. It is known that processing $1 \mathrm{~kg}$ of batteries can release graphite for 20 pencils. Develop an information model that allow to calculate how many batteries should be returned to the processing plant so that graphite can be enough for 100 pencils.

2. SZPO reads the secret location code of the Sith planet from an ancient dagger. After the dagger has been lost, SZPO can play back the secret code. Babu Frick is about to reprogram SZPO. In his memory he has the location code of the planet Sith, which he has read from an ancient dagger. After reprogramming SZPO, he can tell the coordinates of the planet in the Jedi language. For 
decryption, each element of the SZPO memory needs to be added 10. In order to tell the coordinates of the Jedi, you need to output the decrypted memory array.

3. Russia ranks 4 th in carbon dioxide emissions. When using 20 thousand tons of coal, a thermal power plant emits 200 tons of ash and harmful substances into the atmosphere. Develop an information model that allow to calculate how much ash and harmful substances will be released into the atmosphere when using 460 thousand tons of coal.

4. Determine how often a particular character occurs in a line.

A spaceship was launched from planet Earth, but something went wrong during the flight and it crashed on the planet Kukarach. Astronauts from this ship sent an encrypted message to the ASAN center to ask for help. In this message, they encrypted their coordinates and the number of crew members. In this text, each symbol has its own designation, for example:

@ - people

№ - number of light years to the Earth

$\$$ - amount of food left

5. The batteries contain hazardous metals. Zinc is a metal that is part of batteries. Determine if the statement "zinc is a dangerous metal" is true.

6. Harry Potter urgently needs to get to London. He can fly on a lightning broomstick, can use a fireplace, and can fly a dragon. It is known that he has an hour to get to the house of his godfather Sirius. If he flies on a lightning broomstick, he will get great pleasure, because he loves to fly, but it will take 55 minutes.

If he uses a fireplace, he will spend 5 minutes, but he can be noticed by the Ministry of Magic. If he flies on a dragon, then the Muggles will see him, and this violates the Non-disclosure Statute. He needs to choose to get to Sirius not to break anything. What should Harry Potter choose?

The survey results were evaluated on a five-point scale in accordance with the criteria described below.

At the end of the educational process we offered a test in order to evaluate the effectiveness of the proposed approach, which reflects a change in the means, methods and organizational forms of training, focused on the formation of mathematical thinking as a demanded cross-professional skill of future engineers. The control test involved the implementation of an interdisciplinary project focused on mathematical activity and supported by an automated high-tech system. We formulated an educational task, which suggested:

- the ability to analyze the problem field and build mathematical models of problems;

- the ability to integrate knowledge from different industries in solving problems;

- defining novelty of the research;
- the ability to argue actions, reasons, results;

- the ability to make informed conclusions;

- operating with judgments and conclusions;

- setting goals, developing plans, projects in the face of uncertainty;

- the presence of skills in algorithmization, working with the application software environment.

To determine the level of formation of mathematical thinking and mathematical literacy, we used the criteria "very low", "low", "average", "high", "very high".

As it was previously noted, we evaluated the formation of the conscious component of mathematical thinking; mathematical literacy (knowledge of fundamental mathematical laws, the ability to take these laws into account in one's activity, and forecasting probabilistic events).

The levels of formation of mathematical thinking were determined by the methods of generalization; disclosure of essential features of concepts and their relationships; practical and intellectual actions of the student, directly related to the content of mastered concepts, knowledge and ideas; the ability to make assumptions and choose the most optimal option from many possible ones; the ability to express new innovative ideas.

Description of levels of mathematical thinking formation:

"Very high" level: the student showed systematic, deep and complete knowledge on the topic, correctly applied the terminology; independently analyzed factual material based on deep knowledge; understood theories, concepts, information resources and gave them a critical assessment; showed elements of scientific creativity in his work; clearly outlined the goals and objectives of the classification; logically, consistently and reasonably defended the conceptual content of the topic; demonstrated a high level of knowledge and culture of thinking; stylistically competently, correctly and exhaustively answered all additional questions.

"High" level: transfer of individual knowledge to generalized; comparison on a substantial basis with the definition of two or three reasons, lack of knowledge of terminology, classification according to one or two essential features. A student proposed his own hypotheses, but they did not quite correspond to the modeling conditions. He showed elements of scientific creativity; but once or twice was mistaken in designating the goals and objectives of classification. A student quite logically, consistently and reasonably defended the conceptual content of the topic; demonstrated a high level of knowledge and culture of thinking; made one or two non-critical errors in the technical presentation of the results. The answers to an additional questions on mathematical activity were correct, but not always in detail. 
Table 1. Experiment results

\begin{tabular}{lcccc}
\hline Mark & \multicolumn{4}{c}{ Number of participants (people) } \\
\hline & Experimental group (26 students) & Control group (24 students) \\
5 & Before & After & Before & After \\
4 & 0 & 8 & 1 & 3 \\
3 & 4 & 10 & 3 & 4 \\
2 & 14 & 6 & 13 & 12 \\
\hline
\end{tabular}

"Average" level: a student had deep, but not systematized, knowledge on the topic; knew scientific terminology; possessed tools, but not effectively used it; understood the basic theories, concepts and information resources, but could not give them a critical assessment. His work showed elements of scientific creativity; adhered to the goals and objectives of the classification indicated by the teacher; but was not always able to defend the content of the topic; demonstrated skills of creative independent thinking; logically and correctly answered most of the additional questions.

"Low" level: a student had insufficient amount of mathematical concepts, knowledge from the field of computer science, cybernetics, etc.; used terminology, but could not always answer additional questions on the operation of the application and optimization of work; was not able to navigate the basic theories, concepts and information resources; made substantial mistakes in classification; made technical errors and violations of the design requirements when processing the results of the study.

If students showed only fragmented interdisciplinary knowledge; but they did not know how to use special terminology; could not answer additional questions; didn't understand the basic theories, concepts and information resources; could not explain the findings; showed non-independence in the classification and programming of applications; made gross errors in the technical documentation for the design of projects, the level of formation of mathematical thinking was rated "low".

"Excellent" mark corresponded to the levels "high" and "very high", "good" - "average" level, "satisfactory" - "low" level. In all other cases, the mark was "unsatisfactory".

Table 1 shows the results of the interdisciplinary project after the experiment.

Performing a quantitative analysis of the above results, we can conclude that after the experiment, 69\% of the students of the experimental group had a high level of skills and abilities (marks 4 and 5), while initially this percentage was $15 \%$. This means a qualitative improvement in students' outcomes from the experimental group. At the same time, the level of skills in the control group also increased, but not so significantly: after the experiment, only $29 \%$ of the students showed good results (compared to $16 \%$ before the experiment), $70 \%$ of the students remained on average and low level.

\section{The control stage of the experiment}

A statistical analysis of the reliability of the results of the pedagogical experiment was evaluated based on the processing of the data obtained according to the Piersen criterion $\chi 2$. To implement the criterion, the following hypotheses were adopted: the level of formation of skills, abilities and qualities of the experimental group is statistically equal to the level of formation of the control group. Hypothesis H1: the level of formation of skills, abilities and qualities of the experimental group is higher than the level of the control group.

We calculate the value of the statistic of the criterion before ( $\chi 21$ ) and after ( $\chi 2$ 2) the experiment using the online resource http://medstatistic.ru/calculators/ calchit.html. Take a significance level $\alpha=0,05$. In this case $c=4$, which means that the number of degrees of freedom is $v=c-1=3$. According to the distribution tables $\chi 2$ for $v=3$ and $\alpha=0,05$, the critical value of the statistic is 7.82. Thus, we obtain: $\chi^{2} 1<\chi^{2}(1,49<7,82)$, and $\chi^{2} 2>\chi^{2}(8,55>7,82)$. According to the decisionmaking rule, this means that the hypothesis Ho is true before the experiment, and hypothesis H1 is true after the experiment.

\section{DISCUSSIONS}

An analysis of scientific and methodological work on the training of engineering specialists allows to argue that the economy of the future has special requirements for school graduates, but the modern digital educational environment cannot meet them though it has an objectively powerful didactic potential in terms of the formation of mathematical thinking.

Studies have shown that the basis of the digital economy is a synthesis of previously existing material production and digital technologies, supporting the widespread use of "smart products" and providing technical innovations for the country's socio-economic development. Despite the fact that the digital transformation of the manufacturing sector is already underway, the implementation of technological innovations have problems due to insufficient training of engineering, technical and managerial specialists in terms of mathematical literacy, formation of mathematical culture, and mathematical thinking. 
The theory and methodology of teaching mathematics describes the use of mobile services for quick questioning of students, increasing interactivity and motivation, but the priorities of the modern digital school indicate the additional need for personalizing mathematical training, supporting vocational guidance and supporting professional self-determination of students. The inclusion of technologies for developing own mobile applications in the mathematical activity of students in order to answer the challenges of the digital economy and train the engineers of the future, requires specially organized methodological support (a system of principles, methods, tools and organizational forms).

Objectively, teachers face specific methodological problems and difficulties when they want to include mobile technologies in the research mathematical activity (insufficient language training, the choice of mobile service or software environment due to their diversity, the problem of developing project topics, etc.).

Our experimental assessment confirms a qualitative difference in the level of qualities that form the basis of mathematical thinking, the skills to apply them in communicative, social practice and professional orientation through the structure of living organisms in the process of developing mobile applications.

Students of the experimental group significantly increased the level of mathematical literacy as the basis for the competencies demanded by modern high-tech production. Of particular importance for solving future professional problems in introducing innovations is the fact that the concretization of the content of each interdisciplinary project does not occur on the initiative of a trainer, which is characteristic of the traditional system of teaching mathematics, but is determined by the students themselves. When programming mobile applications, additional opportunities were also created for developing teamwork skills, intersectoral communication, and propaedeutics of working with technical documentation were carried out.

An analysis of the cognitive mathematical activity of future engineering and technical specialists has also confirmed that mobile technologies, due to interactivity and enhanced feedback, and the intensification of information interaction, create additional opportunities for directing mathematics education to the challenges of future professions.

On the other hand, during the experiment, we had to solve problems of a didactic and methodological nature: the manifestation of interdisciplinary knowledge and creativity in the formulation of the themes of the project; the study of specialized literature in mathematics; synchronization of a mobile device and software; the need to search for specialized interactive resources; insufficient level of language training when working with foreign sources of information; large time and labor costs for the technical execution of the project results.

\section{CONCLUSION}

The results of the research prove that the new challenges and requirements of society, state, and business to the education system necessitate the purposeful formation of mathematical thinking as the basis of the demanded competencies of future specialists.

The work contains a clarification of basic concepts necessary for improving the training system for engineers of the future, defining the principles of mathematical education in digital space. An analysis of the results of the cognitive mathematical activity allows to reasonably argue that the use of mobile technologies in the training of future specialists can change teaching methods and means, increase the level of formation of mathematical skills, and prepare students to master the high-tech profession for the digital economy.

The effectiveness of the proposed approach is confirmed by a pedagogical experiment, during which the result of cognitive mathematical activity was evaluated by a set of criteria that correspond to competencies of future professions and the priorities of the digital economy.

The research results can be used:

- to solve didactic problems caused by the introduction of mobile technologies, automated production and the need to maintain a stable balance between the technosphere and the ecosphere;

- within the framework of the implemented model of teaching mathematics, based on the traditional was "preschool education-school-university-additional education" in the context of the new requirements of business, society, and the state for the training of highly qualified professionals of the future;

- to ensure personalization of teaching mathematics due to specially organized areas of support for research activities focused on intellectual development (systemic, mathematical and foresight thinking), and carried out in the conditions of training future specialists capable of making an innovative breakthrough in modern science and technology. Such individualization is realized through the activation of communications and organization of collective, creative, multidisciplinary and cognitive research activities in the formation of fundamental mathematical knowledge;

- for a qualitative change in the nature of the interaction of participants in the mathematical educational process in order to form mathematical literacy, corresponding to the level of information culture of a person, determined by the conditions of his life in a digital society. 


\section{ACKNOWLEDGEMENT}

The study was carried out with the financial support of the State Assignment of the Ministry of Education and Science of the Russian Federation "Teacher Training Technologies in a Classical University Environment", the project № 27.9412.2017/8.9.

\section{REFERENCES}

Alexandrov, D., Ivaniushina, V., \& Simanovsky, D. (2017). Online Educational Resources for Schoolchildren and the Digital Divide. Voprosy Obrazovaniya, Educational Studies Moscow, 3, 183201. https:// doi.org/10.17323/1814-9545-2017-3183-201

Buteau, C., Sacristán, A. I., \& Muller, E. (2019). Roles and Demands in Constructionist Teaching of Computational Thinking in University Mathematics. Constructivist Foundations, 14(3), 294309.

Catarino, P., Vasco, P., Lopes, J., Silva, H., \& Morais, E. (2019). Cooperative learning on promoting creative thinking and mathematical creativity in higher education. REICE.Revista Iberoamericana Sobre Calidad, Eficacia y Cambio En Educacion, 17(3), 5-22.

Chang, M., Chen, C.-T., Wu, K.-H., \& Yu, P.-S. (2019). Conversation Quest in MEGA World (Multiplayer Educational Game for All). Foundations and Trends in Smart Learning. Singapore: Springer. https:/ / doi.org/10.1007/978-981-13-6908-7_10

De Corte, E. (2019). Learning Design: Creating Powerful Learning Environments for Self-Regulation Skills. Voprosy Obrazovaniya / Educational Studies Moscow, 4, 30-46. https://doi.org/10.17323/1814-95452019-4-30-46

Del Río, L. S., Sanz, C. V., \& Búcari, N. D. (2019). Incidence of a hypermedia educational material on the teaching and learning of mathematics. Journal of New Approaches in Educational Research, 8(1), 50-57. https:// doi.org/10.7821/naer.2019.1.334

Dvoryatkina, S. N., Karapetyan, V. S., Dallakyan, A. M., Rozanova, S. A., \& Smirnov, E. I. (2019). Synergetic effects manifestation by founding complexes deployment of mathematical tasks on the chessboard. Problems of Education in the 21st Century, 77(1), 8-21. https://doi.org/10.33225/ pec/19.77.08

Fahuzan, K., \& Santosa, R.H. (2018). Gender differences in motivation to learn math using role play game in smartphone. Paper presented at the Journal of Physics: Conference Series, 1097(1). https:/ / doi.org/ 10.1088/1742-6596/1097/1/012130

Filatova, M.N., Sheinbaum, V.S., \& Schedrovitsky, P.G. (2018). Ontology of competency "ability to work in a team" and approaches to its development in an engineering university. Higher Education in Russia, 27(6), 71-82.

Fouze, A. Q., \& Amit, M. (2018). Development of Mathematical Thinking through Integration of Ethnomathematic Folklore Game in Math Instruction. Eurasia Journal of Mathematics, Science and Technology Education, 14(2), 617-630. https:// doi.org/10.12973/ejmste/80626

Fritsch, M., \& Wyrwich, M. (2019). Regional Emergence of Start-Ups in Information Technologies: The Role of Knowledge, Skills and Opportunities. Foresight and STI Governance, 13(2), 62-71. https:// doi.org/10.17323/2500-2597.2019.2.62.71

Galimova, E., Konysheva, A., Kalugina, O., \& Sizova, Z. (2019). Digital Educational Footprint as a Way to Evaluate the Results of Students' Learning and Cognitive Activity in the Process of Teaching Mathematics. Eurasia Journal of Mathematics, Science and Technology Education, 15(8), 143-150. https:// doi.org/10.29333/ejmste/108435

Gault, F. (2019). User Innovation in the Digital Economy. Foresight and STI Governance, 13(3), 6-12. https:/ / doi.org/10.17323/2500-2597.2019.3.6.12

Ghazali, E.M., Mutum, D.S., \& Woon, M.Y. (2019). Multiple sequential mediation in an extended uses and gratifications model of augmented reality game Pokémon Go. Internet Research, 29(3), 504-528. https:// doi.org/10.1108/IntR-12-2017-0505

Gut, A., \& Mirski, R. (2018). Language as a Necessary Condition for Complex Mental Content: A Review of the Discussion on Spatial and Mathematical Thinking. Roczniki Filozoficzne, 66(3), 33-56. https:/ / doi.org/10.18290/rf.2018.66.3-2

Hamada, M., \& Hasan, M. (2017). An Interactive Learning Environment for Information and Communication Theory. EURASIA Journal of Mathematics, Science and Technology Education, 13(1). https:// doi.org/10.12973/eurasia.2017.00603a

Hamid, S., Ijab, M. T., Sulaiman, H., Md. Anwar, R., \& Norman, A. A. (2017). Social media for environmental sustainability awareness in higher education. International Journal of Sustainability in Higher Education, 18(4), 474-491. https:/ / doi.org/10.1108/IJSHE-01-2015-0010

Harjo, B., Kartowagiran, B., \& Mahmudi, A. (2019). Development of critical thinking skill instruments on mathematical learning high school. International Journal of Instruction, 12(4), 149-166. https:// doi.org/10.29333/iji.2019.12410a

Hill, V., \& Knutzen, K.B. (2017). Virtual world global collaboration: An educational quest. Information and Learning Science, 118(10), 547-565. https:/ / doi.org/10.1108/ILS-02-2017-0010

Hunt, M.G., Marx, R., Lipson, C., \& Young, J. (2018). No More FOMO: Limiting Social Media Decreases 
Loneliness and Depression. Journal of Social and Clinical Psychology, 37(10), 751-768. https:// doi.org/10.1521/jscp.2018.37.10.751

Janelli, M. (2018). E-Learning in Theory, Practice, and Research. Voprosy Obrazovaniya, Educational Studies Moscow, 4, 81-98. https:// doi.org/10.17323/18149545-2018-4-81-98

Kaplunovich, I. Ya., \& Petukhova, T. A. (1998). Five substructures of mathematical thinking: how to identify and use them in teaching. Math at school, 5, $45-48$.

Karabelskaya, I. V. (2017). The use of digital technology in the educational process of higher education. Bulletin of USTU, 1(19), 127-131.

Kholodnaya, M. A., \& Gelfman, E. G. (2016). Development-focused educational texts as a basis for learners' intellectual development in studying mathematics (DET technology). Psychology in Russia: State of the Art, 9(3), 24-37. https:/ / doi.org/10.11621/pir.2016.0302

Kuzminov, Y., Sorokin, P., \& Froumin, I. (2019). Generic and Specific Skills as Components of Human Capital: New Challenges for Education Theory and Practice. Foresight and STI Governance, 13(2), 19-41. https:/ / doi.org/10.17323/2500-2597.2019.2.19.41

Lagunov, A., \& Podorojnyak, N. (2017). The research of the complex of alternative energy to power the satellite container. IEEE EUROCON $2017-17$ th International Conf. on Smart Technologies, 1, 370-375. https://doi.org/10.1109/EUROCON.2017.801113 7

Laso Salvador, S., Ruiz Pastrana, M., \& Marbán Prieto, J. M. (2019). Impacto de un programa de intervención metacognitivo sobre la Conciencia Ambiental de docentes de Primaria en formación inicial. Revista Eureka Sobre Enseñanza y Divulgación de Las Ciencias., 16(2), 1-16.

Lee, M. Y. (2018). Further Investigation into the Quality of Teachers' Noticing Expertise: A Proposed Framework for Evaluating Teachers' Models of Students' Mathematical Thinking. Eurasia Journal of Mathematics, Science and Technology Education, 14(11), em1570. https:// doi.org/10.29333/ ejmste/ 92019

Li, N., Mok, I.A.C., \& Cao, Y. (2019). The evolution of mathematical thinking in chinese mathematics education. Mathematics, 7(3), 396-411. https://doi. org/10.3390/math7030297

Malkawi, E., Alhadrami, S., \& Aljabri, A. (2019). Building an interactive mobile application to enhance students' problem solving skills in higher education physics. Paper presented at the CSEDU 2019 - Proceedings of the 11th International Conference on Computer Supported Education, $2550-555$. https:// doi.org/10.5220/0007780105500555
Mokretsov, R. M., \& Zaslavskiy, M. M. (2018). Platform architecture for development of mobile applications with outdoor-quests. Scientific and Technical Journal of Information Technologies, Mechanics and Optics, 3, 511-520. https://doi.org/ 10.17586/2226-1494-2018-18-3-511-520

Mora-Luis, C.E., \& Martin-Gutierrez, J. (2020). The Change of Educational Processes, Learning and Teaching in Engineering Education. Eurasia Journal of Mathematics, Science and Technology Education, 16(3). https:// doi.org/10.29333/ ejmste/116034

More, M. (2018). Mathematics and engineering in real life through mathematical competitions. International Journal of Mathematical Education in Science and Technology, 49(2), 305-321. https:// doi.org/10.1080/0020739X.2017.1387297

Nagornaya, V. O. (2015). The development of mathematical thinking at school. Concept: scientific journal, 21, 76-80.

Nissen, V., Lezina, T., \& Saltan, A. (2018). The Role of ITManagement in the Digital Transformation of Russian Companies. Foresight and STI Governance, 12(3), 53-61. https:// doi.org/10.17323/2500-2597. 2018.3.53.61

Osipova, S. I., Gafurova, N. V., \& Rudnitsky, E. A. (2019). Formation of Soft skills in the conditions of social and public practices of students in the Implementation of the educational program in the ideology of the CDIO International initiative. Perspectives of Science and Education, 40(4), 91-101. https:// doi.org/10.32744/pse.2019.4.8

Pantseva, E. Yu., Toisheva, O. A., \& Borisova, E. A. (2014). Mathematical thinking is the basis of professional thinking. Humanities, socio-economic and social sciences, 4, 205-207.

Perelet, R. A. (2019). Environmental Issues in a Digital Economy. The World of New Economy, 12(4), 39-45. https:/ / doi.org/10.26794/2220-6469-2018-12-4-3945

Perminov, E. A., Gadjiev, D. D., \& Abdurazakov, M. M. (2019). About relevance of fundamentalisation of mathematical training of students of the pedagogical directions during the digital era. Obrazovanie i Nauka, 21(5), 86-111. https:/ / doi.org/ 10.17853/1994-5639-2019-5-87-112

Petko, D., Schmid, R., Müller, L., \& Hielscher, M. (2019). Metapholio: A Mobile App for Supporting Collaborative Note Taking and Reflection in Teacher Education. Technology, Knowledge and Learning, 24(4), 699-710. https://doi.org/10.1007/ s10758-019-09398-6

Ponomarev, A., \& Dezhina, I. (2016). Approaches to the Formulation of Russia's Technological Priorities. Foresight and STI Governance, 10(1), 7-15. https:/ / doi.org/10.17323/1995-459X.2016.1.7.15 
Radović, S., Marić, M., \& Passey, D. (2019). Technology enhancing mathematics learning behaviours: Shifting learning goals from "producing the right answer" to "understanding how to address current and future mathematical challenges". Education and Information Technologies, 24(1), 103-126. https:/ / doi.org/10.1007/s10639-018-9763-x

Raman, M. (2003). Key ideas: What are they and how can they help us understand how people view proof. Educational studies in mathematics, 52(3), 319325. https:/ / doi.org/10.1023/ A:1024360204239

Ramdani, R., Syamsuddin, A., \& Sirajuddin, S. (2019). Development of Mathematical Module-Problem Solving Approach to Train Student's Reflective Thinking. Pedagogical Research, 4(4), em0040. https://doi.org/10.29333/pr/5861

Roshchina, Y. M., Roshchin, S. Yu., \& Rudakov, V. N. (2018). The Demand for Massive Open Online Courses (MOOC): Evidence from Russian Education. Voprosy Obrazovaniya. Educational Studies Moscow, 1, 174-199. https://doi.org/ 10.17323/1814-9545-2018-1-174-199

Saritas, O. (2013). Human Enhancement Technologies: Future Outlook and Challenges. Foresight-Russia, 7, 6-13. Retrieved from https://foresightjournal.hse.ru/en/2013-7-1/78437104.html

Sayed, F. (2017). ICT, mathematics and critical thinking. Turkish Online Journal of Educational Technology, December Special Issue ITEC, 383-385.

Schiptsova T. A., Schiptsova A. V., \& Mustafina D. A. (2012). Mathematical thinking as the basis of engineering education. Advances in Modern Natural Sciences, 5, 83-84. Retrieved on 14 January 2020 from

Scholtz, B., Burger, C., \& Zita, M. (2016). A Social Media Environmental Awareness Campaign to Promote Sustainable Practices in Educational Environments. B J. Marx Gomez, M. Sonnenschein, U. Vogel, A. Winter, B. Rapp, \& N. Giesen (Ed.), Advances and New Trends in Environmental and Energy Informatics (pp. 355-369). London: Springer International Publishing. https://doi.org/10.1007/978-3-31923455-7_19

Shulgina, T. A., Ketova, N. A., Kholodova, K. A., \& Severinov, D. A. (2018). Motivating students to participate in professionally oriented events management. The Education and Science Journal, 20(1), 96-115. https:/ / doi.org/10.17853/1994-56392018-1-96-115

Smirnov, E. I., Zykova, T. V., \& Tikhomirov, S. A. (2019). The management of school mathematical education with synergistic effect. Perspektivy Nauki i Obrazovania, 37(1), 190-202. https://doi.org/ 10.32744/pse.2019.1.14

Soboleva, E. V., Karavaev, N. L., Shalaginova, N. V., Perevozchikova, M. S. (2018). Improvement of the
Robotics Cross-Cutting Course for Training of Specialists in Professions of the Future. European Journal of Contemporary Education, 7(4). https:/ / doi.org/10.13187/ejced.2018.4.845

Soboleva, E. V., Karavaev, N. L., \& Perevozchikova, M. S. (2017). Improving the content of teacher training for the development and use of computer games in education. Bulletin of the Novosibirsk State Pedagogical University, 6, 54-70. https:/ / doi.org/10.15293/2226-3365.1706.04

Tambunan, H. (2019). The Effectiveness of the Problem Solving Strategy and the Scientific Approach to Students' Mathematical Capabilities in High Order Thinking Skills. International Electronic Journal of Mathematics Education, 14(2), 293-302. https:// doi.org/10.29333/iejme/5715

Taneja, H., Webster, J. G., Malthouse, E. C., \& Ksiazek, T. B. (2012). Media consumption across platforms: Identifying user-defined repertoires. New Media $\mathcal{E}$ Society, 14(6), 951-968. https://doi.org/10.1177/ 1461444811436146

Tregub, L. S. (1973). Elements of the modern introduction to mathematics: Equality. Numerical structures. Tashkent: Fan.

Tsymbalist, O. V., \& Grigoriev, S. I. (2003). Mathematical modeling in the content of engineering education is a tool for the formation of mathematical thinking. Bulletin of Altai State Agrarian University, 12(4), 172 174.

Urvanova, N. A. (2018). A model for the development of mathematical thinking of students in classes of mathematical and natural-science. Innovative Development of Vocational Education, 4(20), 39-45.

Usol'tsev, A. P., \& Antipova, E. P. (2019). Innovative activity of teachers - Myth or reality? The Education and Science Journal, 21(5), 9-41. https:/ / doi.org/10.17853/1994-5639-2019-5-9-42

Zafoschnig, A. (2018). Smart Ideas for Engineers - the Impact of Emerging Technologies on Modern Engineering Education. Higher education in Russia, 27(6), 66-70.

Záhorec, J., Hašková, A., \& Munk, M. (2010). Impact of Electronic Teaching Materials on Process of Education^ $\wedge$ Results of an Experiment. Informatics in Education, 9(2), 261-281.

Zasedatel, V. S., \& Serbin, V. A. (2014). Mobile learning in the concept of modern education. Open and Distance Education, 4(56), 77-85.

Zeynivandnezhad, F., \& Bates, R. (2018). Explicating mathematical thinking in differential equations using a computer algebra system. International Journal of Mathematical Education in Science and Technology, 49(5), 680-704. https://doi.org/10.1080 /0020739X.2017.1409368 
Varshavskaya, E., \& Kotyrlo, E. S. (2019). Graduates in Engineering and Economics: Between Demand and Supply. Voprosy Obrazovaniya / Educational Studies Moscow, 2, 98-128. https:/ / doi.org/10.17323/18149545-2019-2-98-128
Wilmer, H. H., \& Chein, J. M. (2016). Mobile technology habits: Patterns of association among device usage, intertemporal preference, impulse control, and reward sensitivity. Psychonomic Bulletin $\mathcal{E}$ Review, 23(5), 1607-1614. https://doi.org/10.3758/s13423016-1011-Z

\section{http://www.ejmste.com}

